\title{
Impact of pacing on systemic ventricular function in L-transposition of the great arteries
}

\author{
Sophie C. Hofferberth, MBBS, ${ }^{a}$ Mark E. Alexander, MD, ${ }^{b}$ Douglas Y. Mah, MD, \\ Victor Bautista-Hernandez, MD, ${ }^{\mathrm{a}}$ Pedro J. del Nido, MD, ${ }^{\mathrm{a}}$ and Francis Fynn-Thompson, MD ${ }^{\mathrm{a}}$
}

\section{ABSTRACT}

Objective(s): To assess the impact of univentricular versus biventricular pacing (BiVP) on systemic ventricular function in patients with congenitally corrected transposition of the great arteries (ccTGA).

Methods: We performed a retrospective review of all patients with a diagnosis of ccTGA who underwent pacemaker insertion. From 1993 to 2014, 53 patients were identified from the cardiology database and surgical records.

Results: Overall mortality was $7.5 \%(n=4)$. One patient required transplantation and 3 late deaths occurred secondary to end-stage heart failure. Median follow-up was 3.7 years (range, 4 days to 22.5 years). Twenty-five (47\%) underwent univentricular pacing only, of these, $8(32 \%)$ developed significant systemic ventricular dysfunction. Twenty-eight (53\%) received BiVP, $17(26 \%)$ were upgraded from a dual-chamber system, $11(21 \%)$ received primary BiVP. Fourteen $(82 \%)$ of the 17 undergoing secondary BiVP demonstrated systemic ventricular dysfunction at the time of pacer upgrade, with $7(50 \%)$ demonstrating improved systemic ventricular function after pacemaker upgrade. Overall, 42 $(79 \%)$ patients underwent univentricular pacing, with $22(52 \%)$ developing significant systemic ventricular dysfunction. In contrast, the $11(21 \%)$ who received primary BiVP had preserved systemic ventricular function at latest follow-up.

Conclusions: Late-onset systemic ventricular dysfunction is a major complication associated with the use of univentricular pacing in patients with ccTGA. All patients with ccTGA who develop heart block should undergo primary biventricular pacing, as this prevents late systemic ventricular dysfunction. Preemptive placement of BiVP leads at the time of anatomical repair or other permanent palliative procedure will facilitate subsequent BiVP should heart block develop. (J Thorac Cardiovasc Surg 2016;151:131-9)

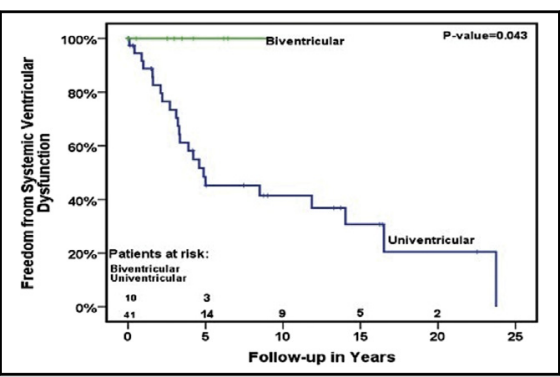

Freedom from late systemic ventricular dysfunction after pacemaker insertion.

\section{Central Message}

All patients with congenitally corrected transposition of the great arteries who develop heart block should undergo primary biventricular pacing, as this therapy appears to prevent development of late-onset systemic ventricular dysfunction

\section{Perspective}

Congenitally corrected transposition of the great arteries (ccTGA) is associated with a high incidence of atrioventricular nodal block due to unique conduction pathway characteristics, associated defects, and surgical interventions. The impact of univentricular versus biventricular pacing (BiVP) on systemic ventricular function remains poorly understood. This study demonstrates univentricular pacing is associated with late-onset systemic ventricular dysfunction, whereas primary BiVP preserves systemic ventricular function in patients with ccTGA. Primary BiVP should be considered in all patients with ccTGA who develop heart block.

See Editorial Commentary page 140.

See Editorial page 15.
From the âDepartment of Cardiac Surgery, Boston Children's Hospital, Harvard Medical School, Boston, Mass; and ${ }^{\mathrm{b}}$ Arrhythmia Service, Department of Cardiology, Boston Children's Hospital, Harvard Medical School, Boston, Mass.

Read at the 95th Annual Meeting of The American Association for Thoracic Surgery, Seattle, Washington, April 25-29, 2015.

Received for publication April 28, 2015; revisions received July 22, 2015; accepted for publication Aug 11, 2015; available ahead of print Sept 23, 2015.

Address for reprints: Francis Fynn-Thompson, MD, Department of Cardiac Surgery,

Boston Children's Hospital, 300 Longwood Ave, Boston, MA 02115 (E-mail: francis.fynn-thompson@cardio.chboston.org).

$0022-5223 / \$ 36.00$

Copyright (c) 2016 by The American Association for Thoracic Surgery

http://dx.doi.org/10.1016/j.jtcvs.2015.08.064
Congenitally corrected transposition of the great arteries (ccTGA) is a rare congenital cardiac anomaly with a wide spectrum of morphologic features and clinical profiles. ${ }^{1,2}$ It is defined by the presence of ventriculoarterial and atrioventricular (AV) discordance. The double discordant connection allows for survival with the right ventricle (RV) performing as the systemic ventricle, and the left ventricle (LV) as the pulmonary ventricle. Critically, native ccTGA physiology is associated with deleterious long-term outcomes, culminating in decreased life expectancy. For patients who remain unoperated and those who 


$$
\begin{aligned}
& \text { Abbreviations and Acronyms } \\
& \begin{aligned}
\text { AV } & =\text { atrioventricular } \\
\mathrm{BiVP} & =\text { biventricular pacing } \\
\mathrm{BT} & =\text { Blalock-Taussig } \\
\text { ccTGA } & =\text { congenitally corrected transposition of } \\
& \text { the great arteries } \\
\mathrm{CRT} & =\text { cardiac resynchronization therapy } \\
\mathrm{ECMO} & =\text { extracorporeal membrane oxygenation } \\
\mathrm{I}, \mathrm{D}, \mathrm{D}=\text { inversus, dextro, dextro } & \\
\mathrm{LV} & =\text { left ventricle } \\
\mathrm{LVEDV} & =\text { left ventricular end-diastolic volume } \\
\text { LVEF } & =\text { left ventricle ejection fraction } \\
\mathrm{PAB} & =\text { pulmonary artery banding } \\
\mathrm{RV} & =\text { right ventricle } \\
\mathrm{S}, \mathrm{L}, \mathrm{L} & =\text { situs solitus } \\
\text { L-loop } & =\text { aorta to left pulmonary artery } \\
\text { VSD } & =\text { ventricular septal defect }
\end{aligned}
\end{aligned}
$$

undergo physiologic repair, the morphological right ventricle is left to support the systemic circulation, leading to late-onset RV dysfunction and concomitant systemic AV regurgitation. ${ }^{3,4}$ To address these poor late outcomes, surgical management has largely evolved from physiologic to anatomic repair in an effort to restore the morphological LV into the systemic circulation. ${ }^{5-12}$ However, although anatomical repair of ccTGA is associated with excellent perioperative and intermediate outcomes, development of late-onset systemic ventricular dysfunction remains a significant problem. . 7,13

Recent reports have demonstrated an association between pacemaker implantation and the development of late-onset systemic ventricular function in patients with ccTGA after anatomical repair. ${ }^{5,13}$ More specifically, univentricular (dual-chamber) pacing has been shown to be a significant risk factor for ventricular dysfunction, whereas biventricular pacing (BiVP) appears to preserve systemic ventricular function. ${ }^{13}$ These results suggest ventricular dyssynchrony plays an important role in the functional deterioration of the systemic ventricle in patients with ccTGA. The goal of this study was to evaluate the impact of univentricular pacing versus BiVP on systemic ventricular function and further elucidate whether the use of BiVP as a primary or secondary (upgrade) mode of pacing prevents late systemic ventricular dysfunction in patients with ccTGA. Herein we report a series of 53 consecutive patients with a diagnosis of ccTGA who underwent pacemaker insertion over a 21-year time period.

\section{MATERIALS AND METHODS \\ Data Collection}

The institutional review board at our institution approved this retrospective study and waived the need for individual patient consent. Patients were identified by using the cardiology database and surgical records at Boston Children's Hospital. Medical records were reviewed for demographic characteristics and treatment indications. The pacemaker type (single vs dual chamber), location of ventricular lead (anatomic LV vs RV, subpulmonary vs subsystemic), and ventricular function before pacemaker implantation, at the time of discharge, and at most recent follow-up after pacer implantation were recorded. For patients who underwent biventricular pacemaker insertion, age at BiVP, indication for primary BiVP, or upgrade from univentricular pacing, and qualitative ventricular (LV and RV) function before and after BiVP implantation were recorded. Posterior-anterior and lateral chest plain films performed after pacemaker insertion, operative notes, and catheterization images were reviewed to determine ventricular lead position.

Qualitative ventricular function was evaluated via echocardiography. Patients with moderate or severe systolic dysfunction on echocardiography were defined as having "significant ventricular dysfunction." Quantitative measures for LV end-diastolic volume (LVEDV) and LV ejection fraction (LVEF) were limited due to image quality, anatomic geometry, and dyssynchrony; therefore, qualitative analysis was deemed more reproducible. RV and LV function was measured before initial pacemaker insertion, at the time of upgrade to BiVP (if applicable), and at the time of most recent echocardiographic follow-up.

Electrocardiograms were examined for QRS morphology and duration before pacemaker insertion, at the time of discharge, and at latest follow-up. Student $t$ test was used to compare median QRS duration between patients who exhibited systemic ventricular dysfunction and those with preserved function.

\section{Statistical Analysis}

The primary outcome variable was the qualitative assessment of systemic ventricular dysfunction as measured by the most recent echocardiogram after pacemaker insertion. Continuous variables were expressed as a median and interquartile range, unless otherwise indicated. Relationships between patient and surgical characteristics and the development of systemic ventricular dysfunction were examined using the Fisher exact test; continuous variables, such as age and weight at time of pacer insertion, were categorized before analysis. A $P \leq .05$ was considered statistically significant.

\section{RESULTS \\ Patient Characteristics}

From April 1993 to January 2014, 53 consecutive patients ( 31 male, 22 female) with a diagnosis of ccTGA underwent pacemaker insertion at our institution. Median age at time of initial pacemaker insertion was 1.8 years (range, 6 days to 42 years) and the median weight was $10.8 \mathrm{~kg}$ (range, 3.5-69.0 kg). Segmental anatomy was S,L,L (situs solitus, L-loop, aorta to left pulmonary artery) in 49 patients $(92 \%)$ and I,D,D (inversus, dextro, dextro) in 4 patients $(8 \%)$. Levocardia was present in 41 patients $(77 \%)$, dextrocardia was present in $9(17 \%)$, and 3 patients $(6 \%)$ had mesocardia. A total of $42(79 \%)$ patients had associated ventricular septal defect (VSD), including 19 $(36 \%)$ with conoventricular VSD, 11 (21\%) with inlet-type VSD, and 12 patients $(23 \%)$ with muscular VSD. Other associated cardiovascular anomalies included pulmonary stenosis in $25(47 \%)$, pulmonary atresia in 10 $(19 \%)$, Ebstein-like anomaly of the left-sided tricuspid valve in $9(17 \%)$, single coronary artery in $3(6 \%)$, and discontinuous pulmonary arteries in $1(2 \%)$ patient. 


\section{Patient Mortality}

In-hospital mortality rate was $2 \%(\mathrm{n}=1)$. This was a 6-month-old infant with ccTGA and RV dysfunction secondary to marked tricuspid and aortic valve regurgitation. After developing respiratory insufficiency that required intubation, she developed intermittent $\mathrm{AV}$ block and subsequently underwent pulmonary artery banding (PAB) and univentricular pacemaker implantation. Her postoperative course was complicated by multiple failed extubation attempts and worsening RV failure, necessitating extracorporeal membrane oxygenation (ECMO) support. One month after initial pacemaker insertion she underwent aortic and tricuspid valve repair and upgrade to a biventricular pacemaker. She was successfully decannulated from ECMO postoperatively with stable hemodynamics; however, she developed neurological deficits and subsequent head computed tomography revealed diffuse hypoxic-ischemic changes with severe volume loss and laminar necrosis. She ultimately died 3 weeks later.

One patient in this series required heart transplantation. This child developed spontaneous heart block at 9 months of age and underwent PAB plus univentricular pacemaker implantation. He then underwent Mustard plus arterial switch repair at 2 years of age. In the initial postoperative period he developed biventricular failure and was upgraded to a biventricular pacemaker. However, his ventricular function failed to improve and he ultimately received a heart transplant 6 months after anatomical repair.

Late mortality rate was $6 \%(\mathrm{n}=3)$. One patient with pulmonary atresia and multiple aortic to pulmonary artery collaterals underwent anatomic repair with Mustard atrial baffle and Rastelli LV to aortic baffle. He subsequently developed AV block and underwent univentricular pacer insertion on postoperative day 10 . The patient died secondary to right heart failure 2 years after univentricular pacemaker insertion. Another patient, an 18-year-old male with ccTGA and VSD, underwent Mustard plus arterial switch repair that was complicated by postoperative heart block, leading to univentricular pacemaker insertion. He developed severe LV dysfunction and was upgraded to a biventricular pacer 6 months later; however, he continued to demonstrate severe LV dysfunction and was subsequently listed for heart transplantation. Unfortunately, he died while on the transplant waiting list. The remaining patient had associated VSD, pulmonary atresia, and multiple aortic to pulmonary artery collaterals. He underwent Blalock-Taussig (BT) shunt repair and univentricular pacemaker insertion for complete heart block and was palliated with an extracardiac Fontan procedure at 3 years of age. He developed severe ventricular dysfunction and symptoms of end-stage heart failure that necessitated prolonged hospitalization and listing for heart transplantation. He ultimately died at age 5 while awaiting heart transplantation.
TABLE 1. Timing/indication for pacemaker insertion

\begin{tabular}{lc}
\multicolumn{1}{c}{ Variable } & Number (\%) \\
\hline Spontaneous heart block & $8(15)$ \\
Time of surgical intervention preparing for & $9(17)$ \\
$\quad$ anatomic repair & \\
PAB & $8(15)$ \\
BT shunt & $1(2)$ \\
Time of anatomical repair & $8(15)$ \\
Post anatomical repair & $28(53)$ \\
\hline$P A B$, Pulmonary artery banding; $B T$, Blalock-Taussig.
\end{tabular}

\section{Outcomes of Univentricular Versus Biventricular Pacing}

Median duration of follow-up was 3.7 years (range, 4 days to 22.5 years). Timing of pacemaker insertion and concurrent surgical procedures are outlined in Table 1. Among the $8(15 \%)$ who developed spontaneous heart block and underwent pacer insertion, $4(50 \%)$ had a systemic LV and 4 had a systemic RV. The $9(17 \%)$ patients who underwent pacer insertion at the time of PAB or BT shunt repair all had a systemic RV. Forty-two (79\%) patients had dual-chamber univentricular pacemakers implanted. Twenty-two (52\%) of the 42 who underwent primary univentricular pacing developed significant systemic ventricular dysfunction. Of these, 11 had a systemic LV, and 11 patients had a systemic RV at the time of developing systemic ventricular dysfunction.

Fourteen $(64 \%)$ of the 22 patients were upgraded to BiVP after developing significant systemic ventricular dysfunction. Seven $(50 \%)$ of the 14 upgraded patients demonstrated improvement in their systemic ventricular function (ie, normal or only mildly impaired systemic ventricular function at latest echocardiographic followup). Of these 7, 4 had a systemic LV, and 3 had a systemic $\mathrm{RV}$ at the time of univentricular pacer insertion. Median age at time of initial pacemaker insertion was 0.5 years (range, 1 month to 18 years). Four of the 7 underwent BT shunt repair or $\mathrm{PAB}$ procedure at the time of univentricular pacer insertion. All 7 underwent anatomical repair after initial pacemaker insertion and were subsequently upgraded to BiVP after developing ventricular dysfunction after anatomical correction. Median time from initial univentricular pacer insertion and upgrade to BiVP was 2.5 years (range, 5 months to 8.5 years).

Seven $(50 \%)$ of the 14 patients upgraded to BiVP did not demonstrate improvement in systemic ventricular function. Three had a systemic LV, and 4 patients had a systemic RV at the time of initial univentricular pacer insertion. Median age at time of initial univentricular pacemaker insertion was 4.3 years (range, 6 months to 22 years). Five of the 7 underwent $\mathrm{BT}$ shunt repair or $\mathrm{PAB}$ procedure; 2 patients underwent concurrent univentricular pacer insertion, and 3 underwent pacemaker insertion subsequent to initial surgical intervention. Four patients underwent anatomical 


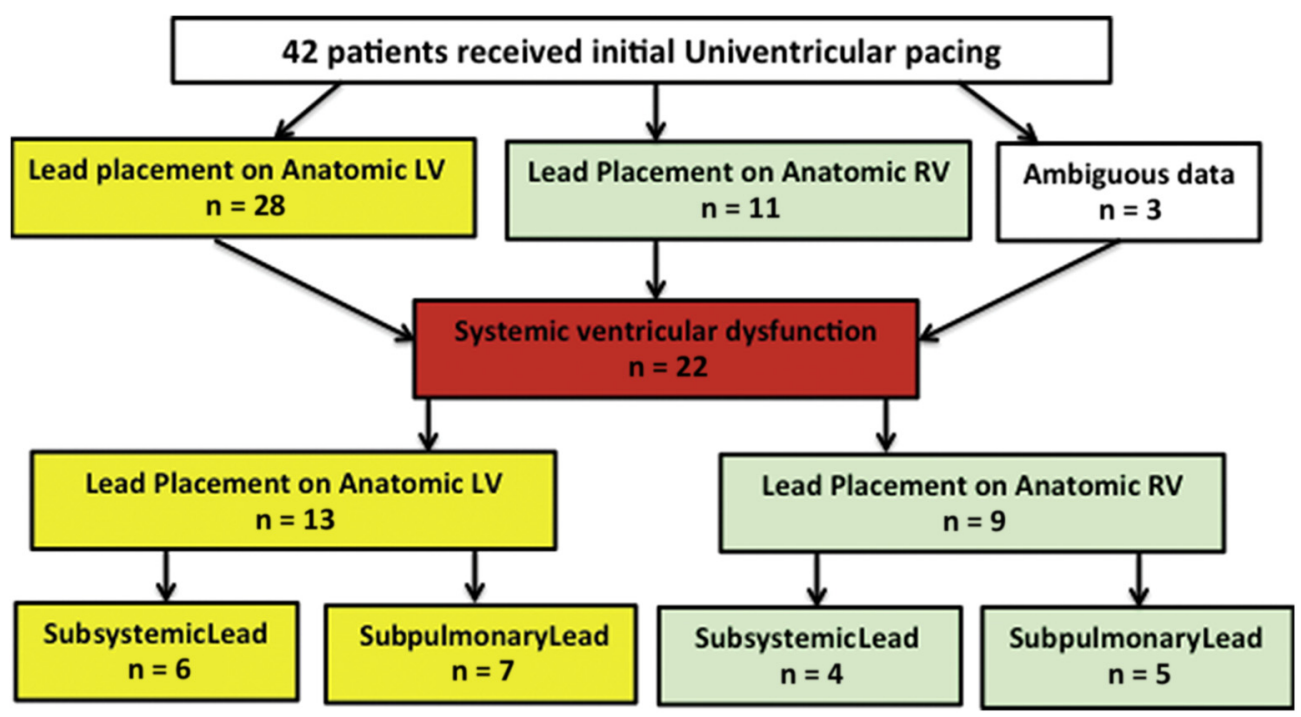

FIGURE 1. Outcomes of primary univentricular (dual-chamber) pacemaker insertion. $L V$, Left ventricle; $R V$, right ventricle.

repair; all 4 were upgraded to BiVP after developing ventricular dysfunction after anatomical correction. Of the other 3 patients, 2 were upgraded to BiVP after their initial $\mathrm{PAB}$ procedure, the other patient underwent aortic and tricuspid valve repair at the time of BiVP upgrade. Median time from initial univentricular pacer insertion and upgrade to BiVP was 4.5 years (range, $0.2-20$ years).

An additional 3 patients were upgraded to BiVP at the time of anatomical repair at the discretion of the operating surgeon, as each of these 3 patients had normal or only mildly impaired systemic ventricular function at the time of upgrade to BiVP. Overall, 27 (64\%) of the 42 patients who underwent initial primary univentricular pacing exhibited normal or only mildly impaired ventricular function at latest follow-up. Figure 1 demonstrates the outcomes of primary univentricular pacing. In contrast, none of the $11(21 \%)$ patients who received primary BiVP developed systemic ventricular dysfunction. Eight $(73 \%)$ patients had a systemic LV, and $3(27 \%)$ had a systemic RV at the time of BiVP insertion.

Freedom from systemic ventricular dysfunction is shown in Figure $2(\log$ rank test, $P=.043)$. An analysis of potential risk factors for late LV dysfunction is shown in Table 2. Interestingly, late-onset systemic ventricular dysfunction was not related to weight greater $20 \mathrm{~kg}$, age older than 10 years, or severe neo-aortic regurgitation, as previously reported. ${ }^{13}$

\section{QRS Duration and Systemic Ventricular Function}

Among the $42(79 \%)$ patients who underwent primary univentricular pacing, median QRS duration immediately before pacemaker implantation was $111 \mathrm{~m} / \mathrm{s}$ (range, $56-212 \mathrm{~m} / \mathrm{s}$ ). Of the 22 patients who subsequently developed systemic ventricular dysfunction, median paced
QRS duration at latest follow-up or at the time of BiVP upgrade was $158 \mathrm{~m} / \mathrm{s}$ (range, $56-212 \mathrm{~m} / \mathrm{s}$ ). The other 20 patients who received univentricular pacing and who maintained normal ventricular function at latest follow-up had a median paced QRS duration of $138 \mathrm{~m} / \mathrm{s}$ (range, 94-186 m/s). There was no significant difference in QRS duration between these 2 groups $(P=.43)$. In the 11 $(21 \%)$ who underwent primary BiVP, median QRS duration was $82 \mathrm{~m} / \mathrm{s}$ (range, $68-138 \mathrm{~m} / \mathrm{s}$ ) before BiVP implantation, compared with a median paced QRS duration of $111 \mathrm{~m} / \mathrm{s}$ (paced, range, 102-254 m/s) at latest follow-up.

\section{Outcomes Based on LV Versus RV Lead Placement}

The relationship between systemic ventricular function and pacing lead location is outlined in Figure 3. Although not statistically significant, there was a trend toward an association between univentricular pacer lead placement

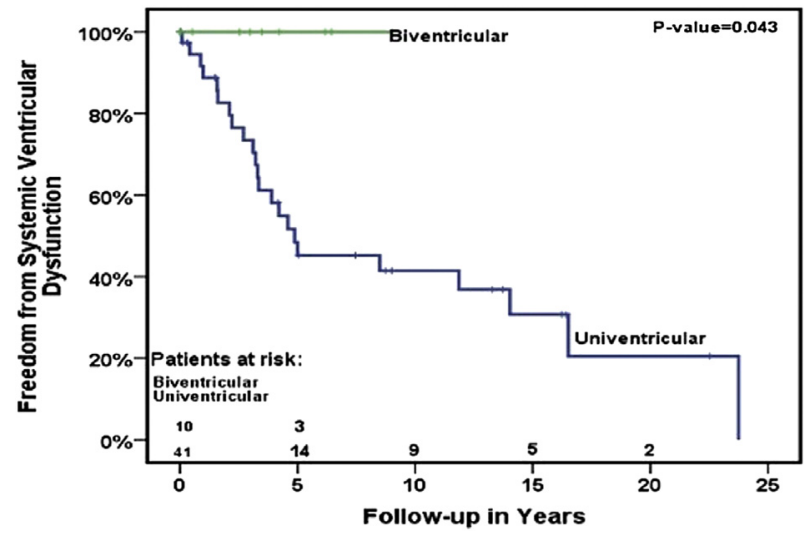

FIGURE 2. Freedom from late systemic ventricular dysfunction after pacemaker insertion. 
TABLE 2. Univariate analysis of patient and operative risk factors for development of systemic ventricular dysfunction

\begin{tabular}{|c|c|c|c|}
\hline Risk factor & Number & $\begin{array}{c}\text { Systemic } \\
\text { ventricular } \\
\text { dysfunction, } \\
\text { number }(\%)\end{array}$ & $\begin{array}{c}P \\
\text { value } \\
\end{array}$ \\
\hline Age at initial pacemaker insertion & & & .260 \\
\hline$<1$ & 19 & $11(57.9)$ & \\
\hline $1-9$ & 24 & $9(37.5)$ & \\
\hline$\geq 10$ & 10 & $2(20.0)$ & \\
\hline Weight at initial pacemaker insertion & & & .255 \\
\hline$<9$ & 19 & $11(57.9)$ & \\
\hline $10-19$ & 18 & $7(38.9)$ & \\
\hline$\geq 20$ & 16 & $4(25.0)$ & \\
\hline Segmental anatomy & & & .094 \\
\hline $\mathrm{S}, \mathrm{L}, \mathrm{L}$ & 49 & $22(44.9)$ & \\
\hline $\mathrm{I}, \mathrm{D}, \mathrm{D}$ & 4 & $0(0.0)$ & \\
\hline Pulmonary stenosis & & & 407 \\
\hline No & 28 & $14(50.0)$ & \\
\hline Yes & 25 & $8(32.0)$ & \\
\hline Pulmonary atresia & & & .730 \\
\hline No & 43 & $17(39.5)$ & \\
\hline Yes & 10 & $5(50.0)$ & \\
\hline Ebstein anomaly & & & 1.000 \\
\hline No & 44 & $18(40.9)$ & \\
\hline Yes & 9 & $4(44.4)$ & \\
\hline BT shunt & & & .501 \\
\hline No & 42 & $16(38.0)$ & \\
\hline Yes & 11 & $6(54.5)$ & \\
\hline PAB & & & .079 \\
\hline No & 37 & $12(32.4)$ & \\
\hline Yes & 16 & $10(62.5)$ & \\
\hline Atrial switch & & & .481 \\
\hline Mustard & 28 & $12(42.9)$ & \\
\hline Senning & 15 & $5(33.3)$ & \\
\hline Other & 9 & $4(44.4)$ & \\
\hline None & 1 & $1(100.0)$ & \\
\hline Arterial switch & & & .526 \\
\hline ASO & 29 & $12(41.4)$ & \\
\hline Rastelli & 14 & $5(35.7)$ & \\
\hline Other & 9 & $4(44.4)$ & \\
\hline None & 1 & $1(100.0)$ & \\
\hline Initial PPM type & & & .001 \\
\hline Univentricular & 42 & $22(52.3)$ & \\
\hline Biventricular & 11 & $0(0.0)$ & \\
\hline Secondary upgrade to BiVP & & & $<.001$ \\
\hline No & 25 & $8(32)$ & \\
\hline Yes & 17 & $14(82)$ & \\
\hline
\end{tabular}

$S, L, L$, Situs solitus, L-loop, aorta to left pulmonary artery; $I, D, D$, inversus, dextro, dextro; $B T$, Blalock-Taussig; $P A B$, pulmonary artery banding; $A S O$, arterial switch operation; $P P M$, pacemaker; $B i V P$, biventricular pacing.

on the anatomic RV versus $\mathrm{LV}$ and development of systemic ventricular dysfunction $(P=.07)$. There was no relationship between subsystemic versus subpulmonary lead placement on the anatomic RV or LV and development of systemic ventricular dysfunction $(P=1.00)$.

\section{DISCUSSION}

Many patients with ccTGA survive into adulthood ${ }^{4,14}$; however, long-term sequelae are common with significant associated morbidity and mortality, particularly related to the development of systemic ventricular failure. ${ }^{3-5,7,13}$ Recent series have reported an association between pacemaker implantation and the development of lateonset systemic ventricular function in patients with ccTGA who underwent anatomical repair. ${ }^{5,13}$ In this study, we included all patients with a diagnosis of ccTGA who underwent pacemaker insertion for heart block. We have shown that single-site ventricular pacing is a significant risk factor for the development of late systemic ventricular dysfunction. Importantly, we have also demonstrated that there is no significant difference in risk of developing late systemic ventricular dysfunction based on initial pacing lead location, whether analyzed by ventricular morphology or physiologic function. Finally, we found that all patients who received $\mathrm{BiVP}$ as the primary mode of pacing had preserved systemic ventricular function at latest follow-up.

Cardiac resynchronization therapy (CRT) has become a standard therapy for adult patients with idiopathic or ischemic cardiomyopathy and systemic ventricular dyssynchrony. Numerous randomized clinical trials have shown CRT induces structural and functional LV reverse remodeling, enhances functional status, and reduces mortality in adult patients with interventricular conduction delay and ventricular dysfunction. ${ }^{15-17}$ Furthermore, in the recent BLOCK-HF (Biventricular vs Right Ventricular Pacing in Heart Failure Patients with Atrioventricular Block) trial, St John Sutton et al ${ }^{18}$ demonstrated improved cardiac structure and function among adult patients with symptomatic heart failure who develop heart block and received BiVP compared with those treated with traditional RV (univentricular) pacing. Nonetheless, there is still a paucity of data in the adult population investigating whether primary BiVP prevents the development of ventricular dyssynchrony and subsequent late-onset heart failure in patients with high-degree AV block. The ongoing prospective, multicenter BioPace (Biventricular Pacing for Atrioventricular Block to Prevent Cardiac Desynchronization) study is seeking to address this question by comparing outcomes among patients with $\mathrm{AV}$ block who were randomly assigned to receive either biventricular or standard univentricular RV pacing. ${ }^{19}$

Although BiVP has been well tested in the adult population, no such equivalent clinical studies have been performed in pediatric patients. Initial case reports and small series demonstrated positive results using BiVP in the pediatric and congenital heart disease populations. ${ }^{20-22}$ In addition, BiVP was shown to be a promising adjunct for the treatment of systemic RV failure in pediatric patients with spontaneous or LV pacing-induced 


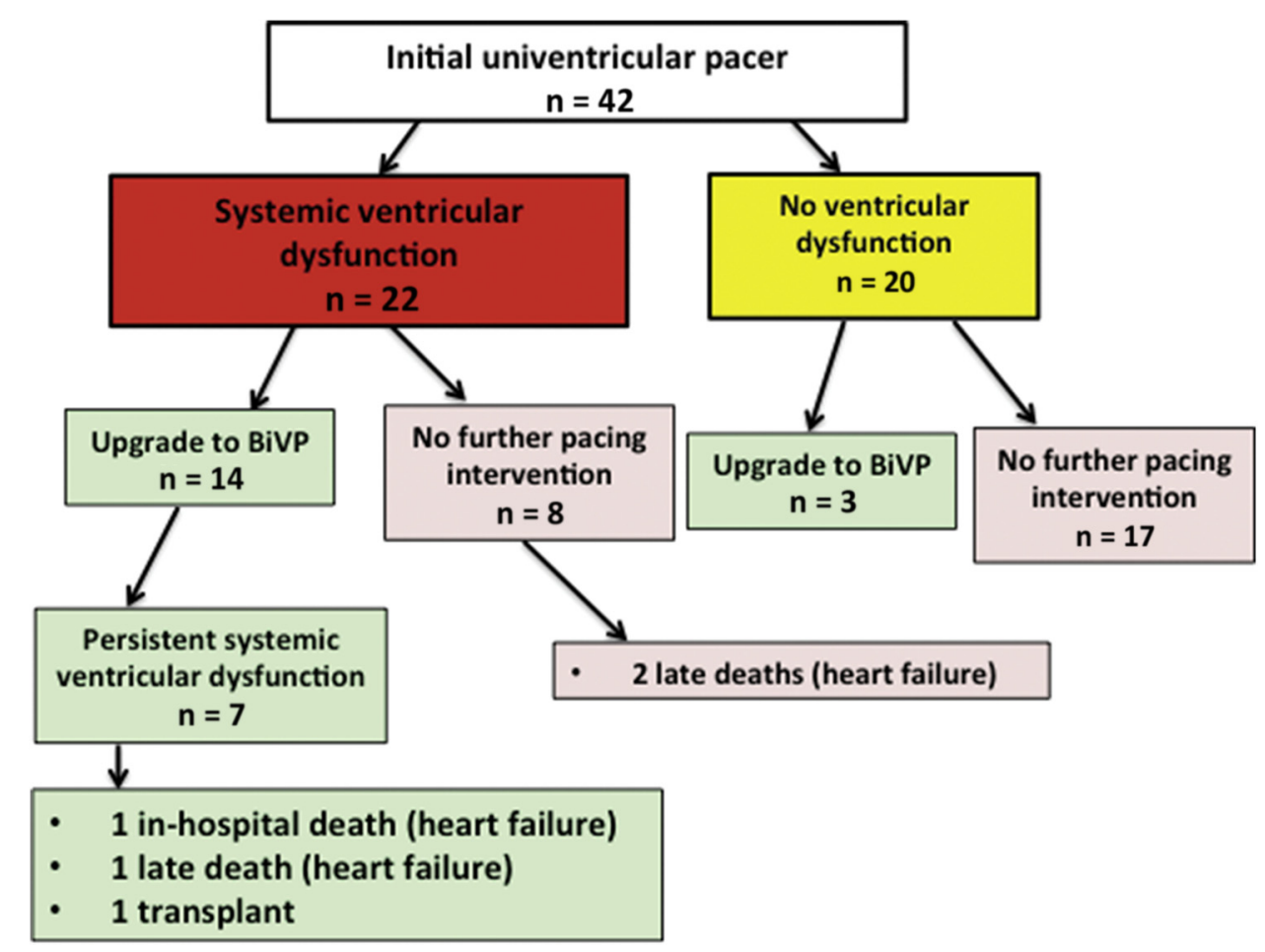

FIGURE 3. Relationship between lead placement and systemic ventricular function. BiVP, Biventricular pacing.

electromechanical dyssynchrony. ${ }^{23}$ However, unfortunately, data investigating the efficacy of BiVP in children remains scarce, with the global experience predominantly limited to just 2 large retrospective case series. ${ }^{24,25}$ These studies showed BiVP decreased QRS duration and improved ventricular function, at least in the short-term, in patients with a variety of congenital cardiac lesions. ${ }^{24,25}$ Yet, others have demonstrated the efficacy of BiVP in pediatric patients varies widely depending on the underlying anatomical or physiological substrate. ${ }^{26}$

Due to a lack of definitive clinical data, no evidencebased treatment protocols currently exist to guide the use of BiVP in children. In particular, reports investigating the efficacy of BiVP in specific lesion sets have been extremely limited. Recently, Mah et $\mathrm{al}^{27}$ demonstrated that BiVP improves left ventricular function in patients with D-loop transposition of the great arteries and VSD who became pacemaker dependent after arterial switch operations. Furthermore, in a recent series analyzing patients with ccTGA who had undergone previous anatomical correction, Bautista-Hernandez et $\mathrm{al}^{13}$ showed that systemic ventricular function is improved when patients are upgraded to BiVP from a dual-chamber single-lead pacing system. In the present study investigating patients with ccTGA who underwent ventricular pacing, 17 children were upgraded to BiVP from a univentricular pacer, 14 of whom had significant ventricular dysfunction at the time of pacemaker upgrade. Seven $(50 \%)$ patients were nonresponders; their ventricular function could not be recovered and 3 ultimately progressed to end-stage heart failure. Unfortunately, our study was underpowered to evaluate for the presence of risk factors for nonresponse to BiVP in this population of patients with ccTGA. Nevertheless, our finding that upgrade to biventricular pacing offers at least short-term improvement in ventricular function among a subset of "responder" patients is aligned with previous studies investigating BiVP efficacy in patients with congenital heart disease. ${ }^{26}$

The encouraging outcomes observed among patients with ccTGA who were upgraded to BiVP has led to a more proactive use of primary BiVP in patients with ccTGA presenting with new-onset heart block to our institution. Furthermore, in select cases, patients deemed at high risk of developing heart block underwent preemptive placement of BiVP leads at the time of anatomical repair. An important finding in this study is that none of the 11 patients who underwent primary BiVP to treat heart block in this cohort of patients with ccTGA developed systemic ventricular dysfunction. This affirms the outcomes reported in our earlier study in anatomically corrected patients with ccTGA. ${ }^{13}$ Based on these results, we recommend that all patients with ccTGA who develop heart block should be considered for primary BiVP.

QRS duration, particularly the presence of left bundle branch block, is a strong predictor of BiVP response in adults with ischemic and nonischemic cardiomyopathy. 
Review of electrocardiographic data in this study demonstrated that QRS duration does not correlate with the ventricular response to BiVP in patients with ccTGA. Although this cohort had the expected trend of narrower QRS in native rhythm, wider QRS in univentricular paced rhythm and intermediate but relatively narrow QRS in BiVP paced rhythm, none of those expected trends was significant. Relative sample size obviously contributed to the lack of significance, in addition, although there are clearly outliers within each group, the median QRS in every group except the univentricular paced group were less than $120 \mathrm{~ms}$.

The current study has a number of limitations. It is retrospective and represents a single-institutional experience. Accurate evaluation of ventricular lead placement was not possible in some patients because of data limitations. Patients who underwent primary univentricular pacing had a greater duration of follow-up compared with those who received BiVP. The observed decline in ventricular function may reflect the natural history of patients with ccTGA with a systemic RV, in addition to being a consequence of single-site pacing. The life table analysis suggests that even if BiVP does not completely prevent development of late ventricular dysfunction, it does at least delay that process. Furthermore, we relied solely on subjective echocardiographic evaluation to classify ventricular function in paced ventricles.

In conclusion, late-onset systemic ventricular dysfunction is a clinically significant complication associated with the use of univentricular pacing in patients with ccTGA. We recommend that any patient with ccTGA who develops heart block should receive primary BiVP, as this prevents the development of systemic ventricular dysfunction. Furthermore, preemptive placement of BiVP leads at the time of anatomical repair or other permanent palliative procedure will facilitate subsequent $\mathrm{BiVP}$ should pacing be needed in ccTGA.

\section{Conflict of Interest Statement}

Authors have nothing to disclose with regard to commercial support.

\section{References}

1. Graham TP Jr, Bernard YD, Mellen BG, Celermajer D, Baumgartner H, Cetta F, et al. Long-term outcome in congenitally corrected transposition of the great arteries: a multi-institutional study. J Am Coll Cardiol. 2000;36:255-61.

2. Warnes CA. Transposition of the great arteries. Circulation. 2006;114:2699-709.

3. Hraska V, Duncan BW, Mayer JE Jr, Freed M, del Nido PJ, Jonas RA. Long-term outcome of surgically treated patients with corrected transposition of the great arteries. J Thorac Cardiovasc Surg. 2005;129:182-91.

4. Sano T, Riesenfeld T, Karl TR, Wilkinson JL. Intermediate-term outcome after intracardiac repair of associated cardiac defects in patients with atrioventricular and ventriculoarterial discordance. Circulation. 1995;92:II272-8.

5. Bautista-Hernandez V, Marx GR, Gauvreau K, Mayer JE Jr, Cecchin F, del Nido PJ. Determinants of left ventricular dysfunction after anatomic repair of congenitally corrected transposition of the great arteries. Ann Thorac Surg. 2006;82:2059-65; discussion 65-6.

6. Di Donato RM, Troconis CJ, Marino B, Carotti A, Iorio FS, Rossi E, et al Combined mustard and Rastelli operations. An alternative approach for repair of associated anomalies in congenitally corrected transposition in situs inversus [I, D,D]. J Thorac Cardiovasc Surg. 1992;104:1246-8.

7. Hiramatsu T, Matsumura G, Konuma T, Yamazaki K, Kurosawa H, Imai Y. Long-term prognosis of double-switch operation for congenitally corrected transposition of the great arteries. Eur J Cardiothorac Surg. 2012;42:1004-8.

8. Ilbawi MN, DeLeon SY, Backer CL, Duffy CE, Muster AJ, Zales VR, et al. An alternative approach to the surgical management of physiologically corrected transposition with ventricular septal defect and pulmonary stenosis or atresia. J Thorac Cardiovasc Surg. 1990;100:410-5.

9. Karl TR, Weintraub RG, Brizard CP, Cochrane AD, Mee RB. Senning plus arterial switch operation for discordant (congenitally corrected) transposition. Ann Thorac Surg. 1997;64:495-502.

10. Reddy VM, McElhinney DB, Silverman NH, Hanley FL. The double switch procedure for anatomical repair of congenitally corrected transposition of the great arteries in infants and children. Eur Heart J. 1997;18:1470-7.

11. Stumper O, Wright JG, De Giovanni JV, Silove ED, Sethia B, Brawn WJ. Combined atrial and arterial switch procedure for congenital corrected transposition with ventricular septal defect. Br Heart J. 1995;73:479-82.

12. Yagihara T, Kishimoto H, Isobe F, Yamamoto F, Nishigaki K, Matsuki O, et al. Double switch operation in cardiac anomalies with atrioventricular and ventriculoarterial discordance. J Thorac Cardiovasc Surg. 1994;107:351-8.

13. Bautista-Hernandez V, Myers PO, Cecchin F, Marx GR, Del Nido PJ. Late left ventricular dysfunction after anatomic repair of congenitally corrected transposition of the great arteries. J Thorac Cardiovasc Surg. 2014;148:254-8.

14. Presbitero P, Somerville J, Rabajoli F, Stone S, Conte MR. Corrected transposition of the great arteries without associated defects in adult patients: clinical profile and follow up. Br Heart J. 1995;74:57-9.

15. Bristow MR, Saxon LA, Boehmer J, Krueger S, Kass DA, De Marco T, et al Cardiac-resynchronization therapy with or without an implantable defibrillator in advanced chronic heart failure. N Engl J Med. 2004;350:2140-50.

16. Cleland JG, Daubert JC, Erdmann E, Freemantle N, Gras D, Kappenberger L, et al. The effect of cardiac resynchronization on morbidity and mortality in heart failure. N Engl J Med. 2005;352:1539-49.

17. St John Sutton MG, Plappert T, Abraham WT, Smith AL, DeLurgio DB Leon AR, et al. Effect of cardiac resynchronization therapy on left ventricular size and function in chronic heart failure. Circulation. 2003;107:1985-90.

18. St John Sutton M, Plappert T, Adamson PB, Li P, Christman SA, Chung ES, et al. Left ventricular reverse remodeling with biventricular versus right ventricular pacing in patients with atrioventricular block and heart failure in the BLOCK HF trial. Circ Heart Fail. 2015;8:510-8.

19. Funck RC, Blanc JJ, Mueller HH, Schade-Brittinger C, Bailleul C, Maisch B. BioPace Study Group. Biventricular stimulation to prevent cardiac desynchronization: rationale, design, and endpoints of the 'Biventricular Pacing for Atrioventricular Block to Prevent Cardiac Desynchronization (BioPace)' study. Europace. 2006;8:629-35.

20. Janousek J, Tomek V, Chaloupecky V, Gebauer RA. Dilated cardiomyopathy associated with dual-chamber pacing in infants: improvement through either left ventricular cardiac resynchronization or programming the pacemaker off allowing intrinsic normal conduction. J Cardiovasc Electrophysiol. 2004;15: 470-4.

21. Rodriguez-Cruz E, Karpawich PP, Lieberman RA, Tantengco MV. Biventricular pacing as alternative therapy for dilated cardiomyopathy associated with congenital heart disease. Pace. 2001;24:235-7.

22. Strieper M, Karpawich P, Frias P, Gooden K, Ketchum D, Fyfe D, et al. Initial experience with cardiac resynchronization therapy for ventricular dysfunction in young patients with surgically operated congenital heart disease. Am J Cardiol. 2004;94:1352-4

23. Janousek J, Tomek V, Chaloupecky VA, Reich O, Gebauer RA, Kautzner J, et al Cardiac resynchronization therapy: a novel adjunct to the treatment and prevention of systemic right ventricular failure. J Am Coll Cardiol. 2004;44:1927-31.

24. Cecchin F, Frangini PA, Brown DW, Fynn-Thompson F, Alexander ME, Triedman JK, et al. Cardiac resynchronization therapy (and multisite pacing) in pediatrics and congenital heart disease: five years experience in a single institution. J Cardiovasc Electrophysiol. 2009;20:58-65.

25. Dubin AM, Janousek J, Rhee E, Strieper MJ, Cecchin F, Law IH, et al Resynchronization therapy in pediatric and congenital heart disease patients: an international multicenter study. J Am Coll Cardiol. 2005;46:2277-83. 
26. Janousek J, Gebauer RA, Abdul-Khaliq H, Turner M, Kornyei L, Grollmuss O, et al. Cardiac resynchronisation therapy in paediatric and congenital heart disease: differential effects in various anatomical and functional substrates. Heart. 2009;95:1165-71.

27. Mah DY, Alexander ME, Banka P, Abrams DJ, Triedman JK, Walsh EP, et al. The role of cardiac resynchronization therapy for arterial switch operations complicated by complete heart block. Ann Thorac Surg. 2013;96:904-9.

Key Words: congenitally corrected transposition of the great arteries, pacemaker, ventricular dysfunction

\section{Discussion}

Dr H. Spotnitz (New York, NY). This study is inspired, innovative, and important. Our concerns include retrospective design, inclusion of double switches, failure to optimize pacing parameters or lead location, and qualitative echocardiography data not validated to current standards.

Nevertheless, the results seem to support preferential CRT rather than unipolar DDD pacing in L-transposition of the great arteries (LTGA) with complete heart block. But a fundamental issue is what mechanism allowed CRT to benefit anatomic RVs powering the systemic circulation.

Two forms of systolic dyssynchrony could be involved. The first is "intraventricular" with CRT reversing regional wall motion abnormalities caused by conduction delays. The second is "interventricular" caused by a timing offset of peak pressures across the interventricular septum. In animals with heart block, CRT allows synchronous transmission of LV pressure to assist the pressure overloaded RV.

In either case, heart block may promote CRT efficacy in these patients by prolonging QRS duration, much as left bundle branch block predicts CRT efficacy in adults with LV dysfunction. Transseptal pressure measurements and echocardiography studies of regional systolic strain and wall thickening may be necessary to define these mechanisms. But the answer might support a multicenter trial addressing whether optimized CRT would decrease late RV failure in all patients with LTGA. We congratulate you on this important research and have 3 questions. First, what is your current clinical practice regarding whether to do CRT and prophylactic lead location?

Dr Hofferberth. The treatment approach at our institution has evolved in recent years whereby our current practice is to perform primary BiVP in every child with LTGA who presents with new-onset heart block.

In terms of the strategy for lead placement, we must take into account that LTGA is a complex lesion, and many of the children we see have complicated associated cardiovascular anomalies and have often undergone previous surgical procedures. These factors make it difficult to locate the site of the latest electrical activation on the ventricle. So essentially the lead placement strategy we have adopted is to place 1 epicardial lead as anterior as possible and then place the other lead posteriorly at the farthest distance possible from the anterior lead, preferably at 90-degree angles to each other.

Dr Spotnitz. Second, what future research are you planning in this area?

Dr Hofferberth. We certainly agree that these results highlight the need to further elucidate the underlying mechanisms that determine whether a patient will respond to CRT. Although it would be difficult to perform a prospective trial in this pediatric population, we think it would be highly beneficial to establish a registry for all patients with LTGA who have received pacemakers and include multiple pediatric cardiac centers. We also think there should be more work done to address optimization strategies that may be used when patients return to follow-up, particularly in those patients who are nonresponders to BiVP. The complicating factor, which is unique to the pediatric population, is that this subset of patients do not respond to BiVP in the same way that adults do, and furthermore their response is not predictable. Therefore, it would be helpful to establish a multicenter database to include a greater number of patients and help us to assess for predictors of response to BiVP.

Dr Spotnitz. Finally, what are your thoughts about the mechanism of action of CRT in these patients?

Dr Hofferberth. From these data, we really cannot come to any conclusion about what the mechanism is behind the response to BiVP. We've deliberately used the term "biventricular pacing" because we can't definitively say that we are resynchronizing the ventricles with this therapy. Also, the electrophysiologists at our institution who follow these patients longitudinally are often forced to use a variety of experimental approaches in an effort to optimize pacing therapy in these patients, because there is so little evidence available to guide the treatment of these patients.

Another important point to make is that when we looked at predictors of response to BiVP that are well described in the adult population, such as QRS duration, we found that these associations do not exist in this cohort of patients. For example, many of the patients who had initial univentricular pacing started off with a narrow QRS complex and were then paced, which led to an expected increase in QRS duration. But, when these patients were upgraded, there was not a significant relationship between upgrade to BiVP and narrowing of the QRS, even in those patients who were responders. So this again demonstrates that the markers of response to BiVP are very different in this pediatric population compared with the adult world.

Dr Spotnitz. We look forward to future work in this area.

Dr Y. Ding (Shenzhen, China). This is a very interesting study. I have 3 questions. Have you encountered any problem, technical problem, and you have to replace the pacing wire? 
Dr Hofferberth. We really did not observe any perioperative complications related to the insertion of the BiVP system. We also did not encounter any issues with fracturing of leads or any other complication of that nature.

Dr Ding. So you used two 5-0 Prolene sutures to tether the lead, right?

Dr Chen. The question is how to secure the epicardial lead.

Dr Ding. I notice some patients will have univentricular pacing and some will have BiVP. This means you used the VVI mode in almost all patients. So would you like to use the DDD pacing?

Dr Hofferberth. I'm not sure I understand your question. I'm not sure if anyone would like to make a comment about that?

Unidentified Speaker. He's asking if you're doing DDD pacing when you talk about unipolar pacing.

Dr Hofferberth. Dr Fynn-Thompson, would you want to address that comment?

Dr Fynn-Thompson. The patients who had univentricular pacing leads were paced using the DDD pacing modality.

Dr M. Mumtaz (San Antonio, Tex). Two clarification questions. The title says this is about LV dysfunction, whereas the reviewer mentioned that there was RV dysfunction? Could you clarify if this is RV or LV dysfunction?

Dr Hofferberth. Essentially, we changed the title to reflect the characteristics of the entire cohort of patients. In this cohort, there were some patients who were paced before they had undergone anatomic repair, and we wanted to make sure that we were incorporating all patients. Therefore, this study is really evaluating systemic ventricular function, so that's why we've changed the title.

Dr Mumtaz. So that kind of muddies the water. In this group of patients, as I now understand, there are patients who have a systemic right ventricle and there are some patients who have had double switches, and they have a systemic left ventricle; is that correct?

Dr Hofferberth. That's correct.
Dr Mumtaz. So they would probably be affected by different parameters and different factors. Why not study the entire cohort but divide them into 2 groups and see?

Dr Hofferberth. The purpose of this study was to assess the impact of pacing in patients with LTGA. We did want to include all patients with a diagnosis of LTGA because this cohort of patients is at such high risk of developing heart block, irrespective of stage of surgical palliation. Really, what we've demonstrated with these results is that even in a heterogeneous group of patients who are at different stages of palliation, BiVP from the outset seems to at least delay development of ventricular dysfunction, so therefore we think the inclusion of all-comers strengthens the results of the study.

Dr Mumtaz. Are there any uncorrected patients in this group?

Dr Hofferberth. Yes, there were 3 patients who were uncorrected throughout follow-up.

Dr Mumtaz. It may help to divide the cohort into 3 groups and analyze them in the article. This would improve our understanding.

Dr J. Chen (Seattle, Wash). I have 1 last practical question, and this may be for Francis also. Double switches and so forth can be complicated, long operations. So, at the end of the case, what's your threshold to put a prophylactic lead on? Is it any heart block, some heart block, a theoretic risk of heart block if you've enlarged VSDs, and so forth?

Dr F. Fynn-Thompson (Boston, Mass). If there is any history of heart block or concern about enlargement of VSD and potential for heart block, we place prophylactic biventricular leads. Other than that, we wouldn't place prophylactic leads if there was no concern of heart block. But if they do develop heart block any time in the postoperative period, then we would come back and place leads.

Dr Chen. So if they develop heart block in the postoperative period and then regain their rhythm again, you'd still go back and place prophylactic leads?

Dr Fynn-Thompson. Yes, we don't trust their conduction, so we place leads. 